\title{
The Logic of History in 'Gap' Discourse and Related Research
}

Author: Sophie Rudolph

Affiliation: Melbourne Graduate School of Education, University of Melbourne Address: 100 Leicester Street, Level 7, University of Melbourne, Vic, 3010, Australia Phone: +61 383449672

Mobile: +61449881524

Email: sophie.rudolph@unimelb.edu.au

\begin{abstract}
The Closing the Gap in Indigenous Disadvantage policy emerged in 2008 following the National Apology to the Stolen Generations. The policy articulates one of its purposes as being to address historical injustices. On the other hand policy reform is naturally oriented to the future in its aims to improve and develop. These temporal tensions are the analytical focus of this article. Through examining the way in which the logic of 'history' is engaged in Australian Indigenous policy and related 'gap' oriented research a range of political effects are illuminated. It is argued that the logic of history is deployed in three key ways: 1) history as over; 2) history as a single presence; 3) history as context. In mapping these different orientations to history in the policy and literature the following questions are asked: how might history be better understood as operating in the present and what sort of transformational possibilities might this afford?
\end{abstract}

Keywords: Indigenous education; history; politics; policy; discourse

\section{Acknowledgements}

I acknowledge Julie McLeod for offering feedback on, and discussions related to, an early draft of this paper. And thanks also go to Luciana Pangrazio and Emma Buchanan for conversations related to an earlier version of this paper. 
The Closing the Gap in Indigenous Disadvantage policy emerged in 2008 following the National Apology to the Stolen Generations. The policy articulates one of its purposes as being to address historical injustices. On the other hand policy reform is naturally oriented to the future in its aims to improve and develop. These temporal tensions are the analytical focus of this article. Through examining the way in which the logic of 'history' is engaged in Australian Indigenous policy and related 'gap' oriented research a range of political effects are illuminated. It is argued that the logic of history is deployed in three key ways: 1) history as over; 2) history as a single presence; 3) history as context. In mapping these different orientations to history in the policy and literature the following questions are asked: how might history be better understood as operating in the present and what sort of transformational possibilities might this afford?

Keywords: Indigenous education; history; politics; policy; discourse

\section{Introduction: Education reform and Time}

Policy is a tool used to direct decisions about educational reform. As a mechanism for improvement it is naturally oriented towards the future and new possibilities. McLeod and Wright observe that 'the promise of the new underpins much educational reform discourse' $(2012,283)$. However, as they demonstrate, the fascination with the new in education policy can manifest in different ways in different times and places and as a result create various effects (McLeod and Wright 2012, 284). In introducing a special issue of the Journal of Educational Administration and History, they note that instead of focusing on the future, the articles engage more robustly 'with the past and with the pastpresent relation, leading us to ask how looking back at utopian sentiments shapes how we might understand and act in the educational present' (McLeod and Wright 2012, 288). This provocation - to contend vigorously with the relationship between past, present and 
future - is taken up in this article.

In the context of the Closing the Gap in Indigenous Disadvantage policy it is less about looking back to utopian sentiments and more a question of how the violence of the past gets understood and negotiated in the present. Through analytical attention to the logic of history, questions are raised about the relationships between past, present and future, and the transformational possibilities greater understanding of this may offer the problem of Australian Indigenous educational disadvantage. While my focus here is largely on the Australian 'closing the gap' discourse and context, some research and perspectives from international contexts are brought into conversation with these in order to illuminate the connected nature of this policy problem and questions of history and politics.

This article begins with a discussion of the logic of history. The idea of history is examined to illuminate how it has been understood in Australia over time offering insight into the politically contested nature of the past. This provides context for the discussion that follows in which the logic of history is scrutinised in both the Closing the Gap policy discourse and related literature. The section addressing the Closing the Gap policy demonstrates how notions of history were central to the development of the policy in 2008. I will argue that the way in which history is positioned in discourse during the advent of the policy is a significant political action. Following this a selection of research literature addressing Indigenous educational disadvantage and gap discourse will be examined with attention to the ways in which the past is understood and contended with. The analysis of this scholarship indicates the possibilities for deeper and more concerted engagement with history for understanding the political work it is doing and the ongoing impact of the past in the present. The final section of the article will raise some questions that emerge out of the analysis in the hope of opening up debate about what a more 
thorough understanding of the ongoing effects of multiple pasts in the present might afford research into Indigenous disadvantage.

\section{Struggles for the Past: History as a 'Logic'}

The way in which concepts are imagined and deployed depends on a range of factors, such as culture, politics and theoretical paradigm. The erasure (or at other times misrepresentation) of history has been the subject of debate in Australia for many decades.

As Indigenous historian John Maynard has argued,

Despite the deep horrors of the Aboriginal experience during the past 216 years, we continue to draw strength and inspiration from the tenacity and courage that our people displayed to survive...History, it is said, is not just about what happened or when it happened, but more importantly why it happened and how it happened. In recognition of that fact, knowledge of history and its importance was for at least three quarters of the 20th century a forbidden zone for Aboriginal Australians. We were not only denied the how and the why but also the what and the when. We were written out of the historical page and efficiently erased from the social landscape. $(2003,139)$

The absence of Indigenous struggles and experiences from the mainstream Australian historical record was acknowledged in 1968 by W.E.H. Stanner, who coined the now famous phrase 'the great Australian silence' (1991, 18). This was a comment on the failure of the Australian state to recognise and contend with the violence and destruction of colonisation and the subsequent Aboriginal dispossession and suffering. This struggle for the past in Australia has been ongoing and indicates what Myers has observed in relation to Irish and Afro-Caribbean histories in England:

This past does not simply arrive in the present through the objective work of scholars, or via the long reach of an individual memory. Instead, both personal and social identities are formed partly from the collective processes of memory and from the selections made and meaning imposed on the past by individuals and groups in contemporary societies. $(2015,2)$

The politics of recording, recounting and reviving Australian history is heavily influenced by what Gillian Cowlishaw describes as the burgeoning of 'Aboriginal history' within 
Australian historiography in the last quarter of the twentieth century $(2006,181)$. Aspects of history that were considered hidden, silenced or ignored were uncovered (Cowlishaw 2006, 181; see also Reynolds 1981, 1989; Haebich 2000, Rowse and Nile 2005), producing a public debate in the 1990s that has become known as the 'history wars' (see for example, Blainey, 1993; Birch, 1997; MacIntyre and Clark, 2003). These heated public 'history wars' give important insight into the political landscape of this historiography. They illustrate four significant points: 1) the power of the colonial project to conceal and distort particular narratives and experiences; 2) the settler-colonial anxiety that is elicited through challenges to the power of the colonial narrative; 3) the role of revisionist histories in restorative justice projects and; 4) the ways in which history often serves political purposes in the present.

The way the past is understood and positioned in both policy discourse and research scholarship is, therefore, important. It offers opportunities for understanding political motivations, ideological paradigms and the kinds of 'taken-for-granted' concepts that are bound up in the proposals offered to the problem of Indigenous educational disadvantage.

\section{Historical Logics in Contemporary Australian Indigenous Education Policy}

Over the past four decades there has been an almost exponential proliferation of policy, reports and strategies produced by Australian State and Commonwealth governments seeking to address the stubborn problem described as Indigenous educational disadvantage (for example, Australian Department of Employment, Education and Training 1989; Commonwealth of Australia 1995; Australian Department of Education, Training and Youth Affairs 1999; Ministerial Council for Education, Early Childhood Development and Youth Affairs 2010). Contemporary engagement with issues of educational disadvantage is similarly, frequently remembered as originating in the early 1970s, 
following the 1967 Referendum that gave the Commonwealth power to legislate on issues directly effecting Indigenous peoples (Mellor and Corrigan 2004, Gray and Beresford 2008, Malin and Maidment 2003). The contemporary focus on disadvantage is, therefore, widely understood as a departure from policies prior to the 1970s that were increasingly recognised as producing Aboriginal suffering 'under a system of discrimination that variously separated, segregated, excluded, "protected" or removed them from their families' (Burridge and Chodkiewicz 2012, 11). The late 1960s appear, therefore, to be remembered as a 'turning point'. This has the effect of demarcating the periods prior to and following the late 1960s in which 'prior to' is understood as a time of neglect and 'following' a time of action.

A similar move seems to occur in the Closing the Gap policy discourse. The development of the policy in 2008 emerged from an understanding of past injustices, the policy discourse being closely tied to the National Apology to the Stolen Generations. In the Apology, then Prime Minister Rudd stated,

The time has now come for the nation to turn a new page in Australia's history by righting the wrongs of the past and so moving forward with confidence to the future...For the future we take heart; resolving that this new page in the history of our great continent can now be written...A future where we harness the determination of all Australians, Indigenous and non-Indigenous, to close the gap that lies between us in life expectancy, educational achievement and economic opportunity. (cited in Moses 2011, 147-148)

The link between history and justice is prominent in this speech and consequently in the policy discourse that was developed concurrently. The disadvantages experienced by Indigenous peoples today are thus widely acknowledged in policy and much research as linked to the history of dispossession and discrimination.

While understanding the link between historical discrimination and present day disadvantage is undeniably important, I contend that the logic of history has other 
simultaneous (and perhaps seemingly contradictory) effects in the policy discourse. In acknowledging the past as the place of injustices towards Indigenous peoples, the discourse reinforces the present as a different time, a new time, a better time. The present (while certainly different, and on some counts better) gets represented in this discourse in a dichotomy with the past. This encourages, I argue, a smoothing over of the complexities of both the past and the present: the past gets seen as 'bad', the present as 'good' (through acknowledgement rather than erasure of the past and the commitment to redemption). While calling history into view, one effect of closing the gap policy then is paradoxically to severe the past from the present rather than to address the diverse ways in which historical legacies continue to animate the present. A further consequence of this is a misrepresentation of structural and embedded inequalities, despite the rhetoric of 'closing the gap' and proclaimed recognition of prior discrimination in which the present is cast as a time/place of redress for past wrongs and not as a time/place in which history is not over. The act of at once seeing and dismissing the past appears then to be an expedient political act within a policy dilemma that is incredibly pressing and complex.

The Closing the Gap policy is also situated within a broader contemporary transnational education discourse that typically ties measurement techniques to a neoliberal education policy regime (Lingard 2011). Critical policy theorists have noted the practice of policy borrowing in this climate (Rizvi and Lingard 2010). The rhetoric of 'closing the gap' appears, therefore, in other contexts. Some have suggested that the term 'closing the gap' originated in the 1990s in New Zealand with government programs designed to target Maori and Pacific Islander disadvantage (Altman et al cited in Bedford et al 2010,39). These programs were, however, highly criticized by Maori people as being associated with unhelpful deficit thinking (Bedford et al, 2010, 39-40). Interestingly this did not prevent the discourse, and the thinking behind it, being taken up in other places. 
For example, the idea of an achievement gap between white students and students of colour in the US has been prominent and debated for over a decade (see Ladson-Billings 2006; Taylor 2006; Rios 2012). And 'gap-talk' related to race is also significant in education in the UK (Gillborn 2008).

The Closing the Gap policy sits within this transnational climate and is influenced by these dynamics, however, less is known about how the positioning of 'the past' impacts the current policy discourse and the subsequent political effects that may contribute to both its dominance as a discourse and its general failure thus far as a strategy. In what follows I examine the way the 'logic' of history appears in a selection of Australian and international research associated with educational disadvantage and the notion of an 'achievement gap'. In doing this I tease out the different types of political work the 'logic' of history can do. This, I argue, raises some questions as to how the concept of history might be engaged in educational research related to historical disadvantage and structural inequalities.

\section{Three Historical Logics: Over, a Single Presence, and Context}

As can be seen in the policy discourse of Closing the Gap, the past is no longer silenced or erased. It is, however, doing some important political work. In this section I examine a selection of research literature for its apparent relationship to history. In doing this, three themes emerge: 1) history as over (and consequently absent); 2) history as a single presence; 3) history as context.

\section{History as Over}

The policy focus on 'the gap' has generated widespread media and educational research engagement with Indigenous related 'issues' centred on the notion of 'gap'. Many research projects have taken up the language of 'gap' to indicate their commitment to 
addressing Indigenous educational disadvantage. Common terminology used in these studies includes 'bridging the gap' (Freeman and Bochner 2008, 9, McConney et al 2011, 2027, Warren and de Vries 2009, Prior 2013, 129, Warren et al 2009), 'closing the gap' (Warren et al 2009, Brasche and Harrington 2012, 111, Prior, 2013, 130) and 'mind the gap' (Wheldall et al 2010, 1). These studies range in scope and purpose, examining different aspects of Indigenous educational disadvantage. For example, the study by Freeman and Bochner focuses on English reading strategies for Indigenous children and families in the Sydney area (2008), while Warren and deVries examine classroom actions in four schools in northern Queensland that supported Indigenous students understanding of western mathematics (2009). The study by Brasche and Harrington focuses on 'factors affecting the quality and continuity of teachers in remote Indigenous communities' (2012, 110) and Prior's work examines the strategies for building Indigenous children's 'school readiness' in order to prepare them for English literacy learning as school, drawing on data from the Western Australian Aboriginal Child Health Survey (2013). While some of these studies explicitly reject a deficit positioning of their work they still tend to focus on outcomes related to parity with non-Indigenous students based on the ability of Indigenous students to perform to already established and stated 'standards' of knowing based on non-Indigenous achievement. This commitment to equality and belief in Indigenous students' capacity to achieve in the western education system is important, but it also fits neatly into the focus of the Closing the Gap policy and as such can reinforce narrowed attention on both what counts as educational success and how the past and future are imagined.

In other studies the notion of gap is taken from the policy discourse to explain disadvantage through reference to various forms of comparative assessment, for example 'the gap between Indigenous and non-Indigenous students mean scores has further 
widened' (Anderson 2012, 197-198; see also, Boon 2008, Leigh and Gong 2009, Wheldall et al, 2010). As the critical scholarship has highlighted (and I will discuss further below) the conceptual orientation of these studies creates the Indigenous subject as needing reform, and as always compared to and constituted in reference to the 'achieving' nonIndigenous subject. While not always intentional, the effect of this positioning is to constitute Indigenous students and communities as in deficit, and in need of reform. These deficit readings of Indigenous achievement, predicated on the achievement of the non-Indigenous student, are further reinforced through persistent descriptors such as: 'at risk' (Koop and Rose 2008, 42, Freeman and Bochner 2008, 9, Ehrich et al 2010, 132, Lyons and Janca 2012), 'chronic under-attenders' (Taylor 2010, 680), 'consistent levels of underachievement' (Faulkner et al 2010, 98) and 'Indigenous children in particular tend to lag far behind their non-Indigenous counterparts' (Ehrich et al, 2010, 131, emphasis added).

It is important to acknowledge that much of this research is concerned with Indigenous educational achievement. It proposes opportunities for assisting Indigenous students such as through providing extra literacy supports at school and their families with greater connection to school (Koop and Rose 2008) and focusing greater attention on the links between better health and education (Lyons and Janca 2012). However, it is also important to examine what other effects this particular focus on Indigenous reform is having. In these studies there is some recognition that history has contributed to the development of a 'gap' in capacity and achievement, however, the emphasis in solutions is forward-focused, future oriented and 'western' knowledge determined. Indigenous knowledges, cultures and languages, for instance, are rarely acknowledged or addressed in this collection of literature. 
This can have the effect of emphasizing the future over the past in such a way that understandings of that history are both presumed as fixed and over. Imagining history in this way means the contested nature of the past can get overlooked - the historical debates among both Indigenous and non-Indigenous people about their hopes and desires for education can be flattened out and the past becomes a place of 'badness' and 'regret'. Added to this, acknowledging history as producing disadvantage, along with the absence of Indigenous knowledge and perspectives as current, can simultaneously reinforce the dominant culture and knowledge system as central and powerful in the present. Indigenous knowledge can then be attached to the past, diminishing its value for the present and future. The dominance of the discourse of diagnosis and remedy of Indigenous students implies that there is one type of gap, one measure of success, one way of achieving, and one historical experience that has created the so-called 'gap' in achievement. This shifts the focus of reform to what is often deemed a 'deviant' individual and away from structural inequalities (and their history).

The orientation to history in current policy and the research examined here, therefore, tends to create particular circumstances for the present that can push the past away when attempting solutions to persistent historical problems of disadvantage. The past is imagined as 'over' and therefore appears to be absent within these proposed solutions to Indigenous educational disadvantage. When history is imagined as 'over' this can also mean 'race' gets erased. The ways in which constructions of race in the past have, and continue, to impact the present can, as a consequence, get overlooked.

\section{History as a Single Presence}

The use of the concept of gap to represent educational disadvantage has garnered much critical attention internationally. In a now famous speech at the national education 
research conference in the United States in 2006, Gloria Ladson-Billings suggested the deficit driven language of 'achievement gap' should be replaced by a commitment to attending to the 'education debt' that is owed to disadvantaged and marginalised students through historical discrimination and exclusion (2006). She states that,

One of the most common phrases in today's education literature is 'the achievement gap'. The term produces more than 11 million citations on Google [...] It has made its way into common parlance and everyday usage. The term is invoked by people on both ends of the political spectrum, and few argue over its meaning or its import. $(2006,3)$

Ladson-Billings points to the ubiquitous nature of the notion of 'achievement gap' and the diverse ways and means in which it is deployed to illustrate educational inequalities. The force and effects of deficit ideas bound up in the dominant discourse of 'gap' for describing disadvantage has been addressed in some Australian research that focuses specific attention to the notion of 'gap' discourse in relation to Indigenous education (Dodson 2010, Lingard et al 2012, Ford 2013, Lester and Munns 2011). Mick Dodson, in a discussion of the challenges and opportunities of Australian Indigenous education, highlights the prevailing and powerful reinforcement of deficiency through 'gap talk':

The notion of 'closing the gap' very easily slides unintentionally into the idea of compensatory schooling - that there is a deficit in our children that must be made up. Or that the languages and cultures of our peoples are part of the problem. $(2010,8)$

Critical policy analysis by Ford (2013) and Lingard et al (2012) also notes the negative impact of deficit language, however, engage further with the role of numbers in bolstering the power of 'gap talk'. The analysis in these pieces takes guidance from British-based research by David Gillborn (2008), which posits that numerical readings of 'gaps' in achievement typically disguise racial inequalities that are 'locked-in' to the education system. Gillborn examines statistical data of student achievement in the UK to establish that, 
Talk of 'closing' and/or 'narrowing' gaps operates as a discursive strategy whereby statistical data are deployed to construct the view that things are improving and the system is moving in the right direction' and that, 'the continual statements that gaps are being 'narrowed', 'reduced' and are 'closing' deliberately feed the impression that incremental progress is removing inequality from the system. $(2008,65)$

Ford (2013) takes a similar approach to investigating 'achievement gap' statistics in Australia, establishing that while public announcements of limited improvement occur, these mask statistics that demonstrate widening of 'the gap' and little significant improvement in outcomes for Indigenous students.

Lingard et al (2012) bring a slightly different lens to their critical analysis of the problem of 'gap talk' in relation to Indigenous students. They suggest that measurement techniques associated with neoliberal forms of governance and the link to NAPLAN in the Closing the Gap policy mean that gap talk can serve to 'ignore past and present practices of (post) colonisation' $(2012,327)$. In this research Lingard and colleagues find that there are counter-productive and silencing effects produced through the coupling of the Closing the Gap policy with the NAPLAN testing regime. They argue that the Closing the Gap policy contributes to decontextualisation of schooling from socio-economic, political and cultural contexts and embedding and naturalisation of educational failure. They draw attention to the 'apparent continuance of deficit thinking, resulting in a 'student-asproblem' framing of education policy focused on 'Indigenous education' $(2012,327)$. They conclude that government priorities guided by the 'closing the gap' policy represent a surreptitious continuation of assimilationist thinking that acts to protect 'white privilege' (Lingard et al 2012, 325-329).

The studies of gap discourse examined above contribute to a broader literature that seeks to highlight the problems of deficit conceptions of Indigenous students and the ways in which this can both reinforce and silence structural inequalities. For example, many 
researchers have drawn attention to the negative consequences of deficit positioning of Indigenous students in policy discourse, educational approaches, classroom relationships and classroom and testing materials (for example, Kerwin 2011, Guenther et al 2013, [Author] 2013, Vass 2014, Rahman 2013). This body of research draws attention to the subtle practices of racism, exclusion and alienation that can occur within education policy and practice that is often positioned with best intentions to assist and benefit students.

The critical scholarship discussed here offers a number of important insights for understanding the effects of the ways in which Indigenous educational disadvantage is positioned in policy and the type of politics that frame its solutions. For instance, it has highlighted the power of 'gap' discourse to view Indigenous students in terms of their individual and collective deficiencies, measured in relation to non-Indigenous student success. Importantly this small but growing body of work illuminates the subtle assimilationist practices such deficit-focused solutions perpetuate. In particular, such research demonstrates the role of statistical data and standardised tests in misrepresenting the educational achievement and challenges of Indigenous and ethnic minority students. The overarching effect of 'gap talk', therefore, is to silence the structural inequalities that contribute to Indigenous educational disadvantage.

This critical work is much more historically engaged, albeit often in implicit or fleeting ways. The discussion of policy priorities having a capacity to be assimilative and the recognition of ongoing colonisation (Lingard et al 2012), for example, draws a continuation between past and present. And the persistence of racism masked by new practices (for example Gillborn 2008, Ford 2013) suggests acknowledgement of racism of the past. There appears, however, to be a focus here on a particular notion of history. For example, while the idea of education debt (Ladson-Billings 2006) transfers the 
responsibility for disadvantage to educational providers and governments rather than individuals seen to have a 'gap', it also seems to see the past exclusively in terms of the lack of provision of education in European knowledge. Similarly, the focus on the masking effects of 'gap talk' and statistical re-examination (Gillborn 2008, Ford 2013), while importantly uncovering inequalities within the European education system, focus on achievement in the dominant system, rather than how the dominant system maintains its dominance in particular ways.

This, I argue, only examines one part of the historical story - that of educational exclusion from European institutions. I suggest this can have two significant effects. First, while there is an important acknowledgement of racial discrimination and its persistence, the focus on this can have the effect of diminishing the understanding of resistance. The historical story then gets told as a straightforward narrative of oppression and discrimination - of course these things are vitally important to wrest but this can cause the struggle and agency of minority groups (in the past and the present) to become diluted or disregarded. A similar concern has been raised related to settler colonial theory (see Macoun and Strakosch 2013). The contested nature of race and the ways in which it has been deployed and opposed can thus be left under-theorised.

Second, while addressing educational exclusion from the dominant system is important, it can have the unintended consequences of reinforcing European educational participation and achievement as central and at the same time diminishing the importance of nonEuropean knowledge and educational practices. Further to this, it can perhaps unwittingly reinforce the centrality of European knowledge in the present, thus continuing practices of the past that are paradoxically expressed as having been left in the past. This can reinforce a modernist conception of time that understands human development to be continually 
advancing and European practices to be the most advanced. Thus the idea that knowledges, such as Indigenous knowledge, are a thing of the past and no longer useful in the present can inadvertently be reinforced, compounding a racially infused idea of a hierarchy of knowledge.

As Jeannie Herbert (2012) argues, the colonial techniques of subjugation of Indigenous peoples produced power relations which cast Indigenous peoples to the periphery and settler in the centre. She notes how 'Aboriginal and Torres Strait Islander knowledges, values and beliefs where totally excluded' (Herbert 2012, 94) from State educational provision. This indicates that the marginalisation of Indigenous knowledge is a longstanding issue and can be linked to colonial practices of exclusion, something that Melinda Miller has explored within the early childhood setting (2015). Much of the critical work (mine included) is focused on interrogating the dominant system. This is of course important and not something I am advocating shying away from. Instead, I suggest that observing this tendency in this body of work may raise a number of questions: How might historical exclusion be repeated and maintained in the present? What are the contestations and challenges to these types of exclusions in both the past and the present? And how might seeing and grappling with such contestations and challenges offer depth of understanding to the ongoing problems of educational disadvantage?

\section{History as Context}

In a recent account of the history of schooling in Australia, Campbell and Proctor (2014) note the limited amount of historical work done in the area of Indigenous education. Weiss, however, has also noted the challenges in generating histories of Indigenous education (2001). Through examples from research with Australian Aboriginal and Canadian First Nations peoples, Weiss highlights the cultural tensions inherent in this 
work in relation to the concepts of education and time (2001, 251-252). She argues that writing 'histories of Aboriginal educational experiences' produces challenges such as 'the difficulty of attempting to analyse and interpret one culture, or set of cultures, through the medium of, and with the tools and methodologies of, another diametrically different culture' (Weiss 2001, 251). This perhaps goes some way to explaining why the small amount of historical work related to Indigenous education tends to be dominated by analyses of policy (see for example, Gunstone 2012, McLeod 2012). It is also perhaps an indication of the marginal place history tends to have in understanding Indigenous education, with the focus (as illustrated in the sections above) more intently on what is considered the urgency of addressing issues of the present and future.

Historical work regarding Indigenous education appears, however, in a number of general texts on Indigenous education. Particularly noteworthy are a collection of edited volumes that examine Indigenous educational issues, policy trends and teaching and learning approaches (Beresford et al 2012, Partington 1998, Harrison 2011, Price 2012, Purdie et al 2011, Craven 2011). Typically history is employed in these texts as a contextualising frame (in the following books it serves this purpose as an early chapter to set up the discussion for the rest of the book: Partington 1998, Price 2012, Beresford et al 2012, Harrison 2011). This historical engagement forms part of the "uncovering of the past' process in which Indigenous experiences with the education system, government authorities and the State is exposed and recognised. This is important history and a move towards coming to terms with the events of the past and rewriting a history of education in which Indigenous people are present. A response perhaps to the points made by John Maynard above. However, there is a danger that this 'restorative' gloss can relegate history to an explanatory role about the past that consequently produces the present as a fresh slate. The result of this is that problems of the past, which can continue to constitute 
the present, may subsequently be smoothed over.

In contrast, in the collection edited by Purdie et al (2011) the 'historical chapter', authored by Bruce Pascoe, deals more directly with the relationship between the past and present. Pascoe suggests that the problems of Indigenous disadvantage that the 'gap discourse' proposes to address relate to 'gaps' in the historical record. He suggests these 'gaps' in historical understanding result in Indigenous peoples continuing to be depicted and understood as 'savages' (Pascoe 2011, 3-9). This historical engagement attempts to examine the effects of history in current debates and not just see it as a backdrop to the present before moving on to solutions to policy and educational problems. This could also be said of a range of research produced prior to the Closing the Gap policy implementation (e.g. McConney 2000; Harrison, 2004; Nakata, 2007). These works do close analysis of the impact of historical power relationships on Indigenous education and policy. This has, however, been ignored in recent years by the focus on the targets suggested through the Closing the Gap policy.

The dilemmas of historical engagement with present day policy problems, which have an understandable forward focus, illustrate some of the challenges for educational reform and social change. In the following section I examine further these challenges and offer some questions to open up debate about the possibilities for historical engagement in the present that contends more thoroughly with issues of race.

\section{Challenges for Wrestling with History as Multiple, Dynamic and Alive in the Present}

This article has outlined some of the temporal tensions within the current policy and research literature that addresses Australian Indigenous educational reform, centered around the national policy of Closing the Gap in Indigenous Disadvantage. Further, this has illuminated the politics of history in the struggle for Indigenous educational equality. 
The concept of history has been shown to be understood and employed in different ways and with different effects.

Three key historical logics were identified across the policy and literature. First, history as over (and consequently absent): this logic, while acknowledging some of the effects of history in the present, overall understands history to remain in the past. The past can then become levered from the present in a way that, while holding the past in view, can fail to seriously attend to ongoing implications of the past in the present. For example, the historical construction of race can be overlooked and the highly contested nature of the struggle for educational reform and justice over many decades can be smoothed over. Second, history as a single presence. Much of the work that employed this logic appears cognisant of the importance of historical awareness and is much more engaged with the idea of history being an ongoing presence. However, in the focus on questioning the dominant system, this work can seem to lose sight of the contestation and negotiation that occurred in the past. This can in turn, inadvertently, reinforce the power and centrality of the dominant system. And third, history as context: this logic clearly positions history as important, typically dealing in detail and explicitly with events of the past. However, by siphoning it off from the present this can suggest that history is a fixed and stable concept only useful for understanding the past. I have suggested that this may limit the capacity to see connections between the past, present and future and to attend to what implications such connections might have for Indigenous educational justice.

I argue, therefore, that more work is required within the field of educational research to wrestle with history - what it means, how it is understood and in what ways it might offer more to the struggle for Indigenous educational justice (and add to a small body of work that has engaged this challenge). I propose this may offer important insights into the 
complexity and continuity of multiple pasts (including the effects of race and racism) that can be overlooked or fleetingly engaged. I am not suggesting this is an easy or straightforward task. And perhaps this is all the more reason to commit concerted effort to collectively attending to such wrestling, embracing the uncertainty and doubt that is bound to appear. Through unsettling taken-for-granted ideas about what history means and does, what appears the straightforward pathway towards future equality may be disturbed, giving some different insights into a policy problem that gets described as intractable (see for example Prime Minister's Office 2015). In doing this both the past and the future may be able to be seen differently, thus opening up a space for new possibilities for Indigenous educational justice.

\section{References}

Anderson, R. (2012). Indigenous students' increasing risk of grade repetition in early schooling. Australian Journal of Indigenous Education, 41(2), 196-207.

Australian Department of Education, Training and Youth Affairs. (1999). National Indigenous English Literacy and Numeracy Strategy 2000-2004. Canberra: Commonwealth of Australia.

Australian Department of Employment, Education and Training. (1989). National Aboriginal and Torres Strait Islander Education Policy. Canberra: Department of Education, Employment and Training.

Bedford, R., Callister, P., \& Newell, J. (2010). Old Gaps are Closing, New Gaps are Opening. In I. Snyder \& J. Nieuwenhuysen (Eds.), Closing the Gap in Education?: Improving Outcomes in Southern World Societies. Melbourne: Monash University Publishing.

Beresford, Q., Partington, G., \& Gower, G. (Eds.). (2012). Reform and resistance in Aboriginal education (Revised ed). Crawley, W.A: UWA Publishing.

Birch, T. (1997). "Black Armbands and White Veils": John Howard's Moral Amnesia. Melbourne Historical Journal, 25, 8-16.

Blainey, G. (1993). Drawing Up a Balance Sheet of our History. Quadrant, 37(7-8), 1015.

Boon, H. J. (2008). Risk or Resilience? What Makes a Difference? The Australian Educational Researcher, 35(1), 81-102. 
Brasche, I., \& Harrington, I. (2012). Promoting teacher quality and continuity: Tackling the disadvantages of remote Indigenous schools in the Northern Territory. Australian Journal of Education, 56(2), 110-125.

Burridge, N., \& Chodkiewicz, A. (2012). An Historical Overview of Aboriginal Education Policies in the Australian Context. In N. Burridge, F. Whalan, \& K. Vaughan (Eds.), Indigenous education: a learning journey for teachers, schools and communities. Rotterdam: Sense.

Campbell, C., \& Proctor, H. (2014). A history of Australian schooling. Crows Nest, N.S.W: Allen \& Unwin.

Commonwealth of Australia. (1995). National Review of Education for Aboriginal and Torres Strait Islander Peoples - Final Report. Canberra: Commonwealth Department of Education, Employment and Training.

Cowlishaw, G. (2006). On "getting it wrong": Collateral damage in the history wars. Australian Historical Studies, 37(127), 181-202.

Craven, R. (Ed.). (2011). Teaching Aboriginal studies (2nd. ed). Crows Nest, N.S.W: Allen \& Unwin.

Dodson, M. (2010). Challenges and Opportunities in Australian Indigenous Education. In I. Snyder \& J. Nieuwenhuysen (Eds.), Closing the Gap in Education?: Improving Outcomes in Southern World Societies. Melbourne: Monash University Publishing.

Ehrich, J., Wolgemuth, J. R., Helmer, J., Oteng, G., Lea, T., Bartlett, C., ... Emmett, S. (2010). Attendance, performance and the acquisition of early literacy skills: A comparison of Indigenous and non-Indigenous school children. Australian Journal of Learning Difficulties, 15(2), 131-149.

Faulkner, S., Ivery, P., Wood, L., \& Donovan, R. (2010). Holyoake's Drumbeat Program: Music as a Tool for Social Learning and Improved Educational Outcomes. The Australian Journal of Indigenous Education, 39, 98-109.

Ford, M. (2013). Achievement gaps in Australia: what NAPLAN reveals about education inequality in Australia. Race Ethnicity and Education, 16(1), 80-102.

Freeman, L., \& Bochner, S. (2008). Bridging the gap: Improving literacy outcomes for Indigenous students. Australian Journal of Early Childhood, 33, 9-16.

Gillborn, D. (2008). Coincidence or conspiracy? Whiteness, policy and the persistence of the Black/White achievement gap. Educational Review, 60(3), 229-248.

Gray, J., \& Beresford, Q. (2008). A “formidable challenge": Australia's quest for equity in Indigenous Education. Australian Journal of Education, 52, 197-223.

Guenther, J., Bat, M., \& Osborne, S. (2013). Red Dirt Thinking on Educational Disadvantage. The Australian Journal of Indigenous Education, 42(2), 100-110.

Gunstone, A. (2012). Indigenous Education 1991-2000: Documents, Outcomes and Governments. The Australian Journal of Indigenous Education, 41(02), 75-84.

Haebich, A. (2000). Broken Circles: Fragmenting Indigenous Families, 1800-2000. Fremantle: Fremantle Press.

Harrison, N. (2004). The Reproduction of Historical Relations in the Crosscultural Classroom at University. Australian Journal of Education, 48(3), 282-294. 
Harrison, N. (2011). Teaching and learning in Aboriginal education (2nd edition). South Melbourne: Oxford University Press.

Herbert, J. (2012). Ceaselessly circling the centre. History of Education Review (Emerald Group Publishing Limited), 41(2), 91-103.

Kerwin, D. W. (2011). When we become people with a history. International Journal of Inclusive Education, 15, 249-261.

Koop, C., \& Rose, D. (2008). Reading to Learn in Murdi Paaki: Changing Outcomes for Indigenous Students. Literacy Learning: The Middle Years, 16(1), 41-46.

Ladson-Billings, G. (2006). From the achievement gap to the education debt: Understanding achievement in US schools. Educational Researcher, 35(7), 3-12.

Leigh, A., \& Gong, X. (2009). Estimating cognitive gaps between Indigenous and nonIndigenous Australians. Education Economics, 17(2), 239-261.

Lester, J., \& Munns, G. (2011). Closing the gap. In R. Craven (Ed.), Teaching Aboriginal studies (2nd. ed, pp. 229-256). Crows Nest, N.S.W: Allen \& Unwin.

Lingard, B. (2011). Policy as numbers: ac/counting for educational research. The Australian Educational Researcher, 38(4), 355-382

Lingard, B., Creagh, S., \& Vass, G. (2012). Education policy as numbers: data categories and two Australian cases of misrecognition. Journal of Education Policy, 27(3), $315-333$.

Lyons, Z., \& Janca, A. (2012). Indigenous children in Australia: Health, education and optimism for the future. Australian Journal of Education, 56(1), 5-21.

MacIntyre, S., \& Clark, A. (2003). The History Wars. Melbourne: Melbourne University Press.

Macoun, A., \& Strakosch, E. (2013). The ethical demands of settler colonial theory. Settler Colonial Studies, 3(3-4), 426-443.

Malin, M., \& Maidment, D. (2003). Education, Indigenous Survival and Well-being: Emerging Ideas and Programs. The Australian Journal of Indigenous Education, 32, 85-95.

Maynard, J. (2003). Australian history - lifting haze or descending fog? Aboriginal History, 27, 139-145.

McConaghy, C. (2000). Rethinking indigenous education: culturalism, colonialism and the politics of knowing. Flaxton, Qld: Post Pressed.

McConney, A., Oliver, M., Woods-McConney, A., \& Schibeci, R. (2011). Bridging the Gap? A Comparative, Retrospective Analysis of Science Literacy and Interest in Science for Indigenous and Non-Indigenous Australian Students. International Journal of Science Education, 33(14), 2017-2035.

McLeod, J. (2012). Educating for "world-mindedness": cosmopolitanism, localism and schooling the adolescent citizen in interwar Australia. Journal of Educational Administration and History, 44(4), 339-359.

McLeod, J., \& Wright, K. (2012). The promise of the new: genealogies of youth, nation and educational reform in Australia. Journal of Educational Administration and History, 44(4), 283-293. 
Mellor, S., \& Corrigan, M. (2004). The case for change: A review of contemporary research on Indigenous education outcomes. Camberwell, Vic: ACER Press.

Miller, M. G. (2015). Consultation with Aboriginal and Torres Strait Islander people in early childhood education: the impact of colonial discourses. Australian Educational Researcher, 42, 549-565.

Ministerial Council for Education, Early Childhood Development and Youth Affairs. (2010). Aboriginal and Torres Strait Islander Education Action Plan 2010-2014. Ministerial Council for Education, Early Childhood Development and Youth Affairs.

Moses, A. D. (2011). Official apologies, reconciliation, and settler colonialism: Australian indigenous alterity and political agency. Citizenship Studies, 15(02), 145-159.

Myers, K. (2015). Struggles for a Past: Irish and Afro-Caribbean Histories in England, 1951-2000. Manchester: Manchester University Press.

Nakata, M. (2007). Savaging the Disciplines, Disciplining the Savages. Canberra: Aboriginal Studies Press.

Partington, G. (Ed.). (1998). Perspectives on Aboriginal and Torres Strait Islander Education. South Melbourne: Thomson Social Science Press.

Pascoe, B. (2011). History: the real gap between black and white. In G. C. Milgate, N. Purdie, \& H. R. Bell (Eds.), Two way teaching and learning: Toward culturally reflective and relevant education. Camberwell, Vic: ACER Press.

Price, K. (Ed.). (2012). Aboriginal and Torres Strait Islander education: an introduction for the teaching profession. Port Melbourne, Vic: Cambridge University Press.

Prime Minister's Office. (2015). Closing the gap: Prime Minister's report 2015. Canberra, A.C.T.: Commonwealth of Australia.

Prior, M. (2013). Language and literacy challenges for Indigenous children in Australia. Australian Journal of Learning Difficulties, 18(2), 123-137.

Purdie, N., Milgate, G. C., \& Bell, H. R. (Eds.). (2011). Two way teaching and learning: Toward culturally reflective and relevant education. Camberwell, Vic: ACER Press.

Rahman, K. (2013). Belonging and learning to belong in school: the implications of the hidden curriculum for indigenous students. Discourse: Studies in the Cultural Politics of Education, 34(5), 660-672.

Rios, V. (2012). Reframing the Achievement Gap. Contexts, 11(4), 8-10.

Rizvi, F., \& Lingard, B. (2010). Globalizing Education Policy. Abingdon: Routledge.

Rowse, T., \& Nile, R. (2005). Contesting assimilation. Perth: API Network.

Stanner, W. E. H. (1991). After the dreaming. Crows Nest, N.S.W: ABC Enterprises for the Australian Broadcasting Corporation.

Taylor, A. (2010). Here and now: the attendance issue in Indigenous early childhood education. Journal of Education Policy, 25, 677-699.

Taylor, E. (2006). A Critical Race Analysis of the Achievement Gap in the United States: Politics, Reality, and Hope. Leadership and Policy in Schools, 5(1), 71-87. 
Vass, G. (2014). The racialised educational landscape in Australia: Listening to the whispering elephant. Race Ethnicity and Education, 17(2), 176-201.

Warren, E., \& deVries, E. (2009). Young Australian Indigenous students' engagement with numeracy: Actions that assist to bridge the gap. Australian Journal of Early Childhood, 53, 159-175.

Warren, E., deVries, E., \& Cole, A. (2009). Closing the Gap: Myths and Truths behind Subitisation. Australasian Journal of Early Childhood, 34(4), 46-53.

Weiss, G. (2001). Inter-disciplinary but not Undisciplined: Writing the history of Aboriginal "education.” Paedagogica Historica, 37(1), 251-261.

Wheldall, K., Beaman, R., \& Langstaff, E. (2010). "Mind the Gap": Effective Literacy Instruction for Indigenous Low-Progress Readers. Australasian Journal of Special Education, 34, 1-16. 


\section{University Library}

\section{- M M N E R VA A gateway to Melbourne's research publications}

Minerva Access is the Institutional Repository of The University of Melbourne

Author/s:

Rudolph, S

Title:

The logic of history in 'gap' discourse and related research

Date:

2016-09-01

Citation:

Rudolph, S. (2016). The logic of history in 'gap' discourse and related research.

AUSTRALIAN EDUCATIONAL RESEARCHER, 43 (4), pp.437-451. https://doi.org/10.1007/ S13384-016-0208-5.

Persistent Link:

http://hdl.handle.net/11343/282615 